\title{
The Research on the Application of the Construction Technology of the Post Pouring Belt in the Basement
}

\author{
Jing Ning Yan \\ Civil Engineering and Architecture School of Nanchang Hangkong University, Nanchang, Jiangxi, \\ 330063, China \\ 2248602417@qq.com
}

Keywords: The post pouring belt; Construction technology; Baseboard; Roof; Concrete wall

\begin{abstract}
During the construction, the surrounding environment, engineering geology, hydrogeology will seriously affect the construction quality of the basement project. In order to ensure the construction quality of the basement,the post pouring belt will be set during the construction of the basement. The main function on the construction technology of the post pouring belt are to drop down and prevent concrete cracking. The type of the post pouring belt are the settling post pouring belt, the shrinking post pouring belt and the thermal post pouring belt. The type election of the post pouring belt $\mathrm{s}$ should consider the structure type, the project site, on-site construction conditions. The engineering example is the underground garage engineering. The construction technology of the post pouring belt of the engineering example includes the construction technology of the post pouring belt on the baseboard, the construction technology of the post pouring belt on the wall and the construction technology of the post pouring belt on the roof. The engineering example uses five kinds of quality assurance measures. The prevention of the crack adopts some measures:the temperature control, the control of the mixture ratio, the control of the construction technology, the reasonable maintenance measure.
\end{abstract}

\section{Introduction}

During the construction, the basement project was easily affected by the surrounding environment, engineering geology, hydrogeology and so on, which will seriously affect the construction quality of the basement project. Therefore, the construction company should analyse according to the related content of engineering design and the actual situation of the construction site,use the method of the post pouring belt,and treat the structure of the basement appropriately. In order to reduce the difficulty of the post pouring belt construction,the builder should set the reasonable construction spot of the post pouring belt in the light of the related construction specification and effectively control the construction quality of the post pouring belt. [1]

The post pouring belt usually refers to the cast-in-situ monolithic reinforced concrete structure construction process, in order to prevent the temperature stress, uneven settlement and concrete shrinkage deformation of one or more causes can lead to cracks of main structure, and the temporary reserved for a certain time after the interval closed with concrete.

Because the overall structure of reinforced concrete structure forms the complete structure by the post pouring belt, the post pouring belt construction quality closely relates the structure quality.

But the post pouring belt is often of large section, more frequent reinforcement, the post pouring belt on both sides of the plate is also provided with a water stop belt, formwork and the cleaning is difficult, if not handled properly, can easily cause the post pouring belt parts of cracks and leakage and other quality problems. [2] 


\section{The type of the post pouring belt}

The settling post pouring belt. The main role is to solve the high-rise building and the podium settlement difference. [3]

The shrinking post pouring belt. The main role is to prevent the shrinkage cracking of concrete.

The thermal post pouring belt. The main role is to prevent the crack of concrete due to temperature change.

\section{The functional analysis on the construction technology of the post pouring belt}

The elimination of differential settlement.The structure and the basement of the high-rise buildings and low rise buildings as a whole. During the construction, the post pouring belt separate the whole. After the construction of the main structure, the structure and foundation of high-rise buildings and low rise building basement has completed most of the settlement. [4]Then pour the concrete of the connection part. High and low layer can be connected into a whole. Therefore eliminate the structure and basement of high-rise buildings and low rise building settlement. [5]

To prevent condensation of concrete shrinkage cracking and to prevent the concrete due to temperature change. In the underground engineering, the new pouring concrete shrinkage occurs in the hardening process, when the volume expansion will be completed to meet the thermal structure, and will be smaller when encounter cold. [6] The completion of these contracts is usually one or two months after the completion of the construction, but the temperature change is continuous influence on the structure. If the deformation is restricted, in the formation of the structure itself will be a temperature stress, temperature stress is too large will allow member crack. If setting the post pouring belt construction, the concrete free shrinkage, reduce the temperature stress. And the tensile strength of its own can offset part of temperature stress, so as to adapt to the change of temperature effect. [7]

\section{The application analysis on the construction technology of the post pouring belt}

In the underground engineering design, the type selection of the post pouring belt forms should be considered part of the project, structure type, site construction conditions and other factors.

The width of the post pouring belt relates to the thickness of the wall and floor. According to the requirement, the thickness of the bottom $100 \mathrm{~cm}$ above the basement project, joint form, reinforced bar, post pouring belt construction according to the difficult degree of flexibility to determine the post pouring belt width, when the construction is more difficult, post pouring belt width may be appropriate to increase. [8]

For the post pouring band after pouring concrete, it should use the free shrinkage of concrete, to prevent cracking of the joints of new and old concrete shrinkage. No shrinkage concrete in concrete mixed with expansive agent, also can be directly used as expansive cement, slag cement. The strength grade of concrete prepared than the pre cast concrete high strength grades.

For different types of post pouring belt, the casting time of post pouring belt after pouring concrete is different. The contraction of the post pouring belt should be based on the pre cast concrete shrinkage finishing conditions, different cement, water cement ratio, curing condition of concrete, the general should be controlled within 60 days after the construction, such as the time limit for a project is very urgent, but also should be in 2 weeks. [9] Settlement post pouring belt should be the basic completion of settlement in the building, and then pouring the post pouring belt.

\section{The example of the engineering application}

The engineering situation. The project is the underground garage with the construction area of 19669 square meters. The roof and floor, the basement concrete wall in the basement set up 26 post pouring 
belt. Width of $1 \mathrm{~m}$, length of $1563 \mathrm{~m}$. Obviously, the quantity of the post pouring belt in this project is too much,and a large amount of engineering. The profile of the post pouring belt on the baseboard is Fig. 1.The profile of the post pouring belt on the wall and the roof is Fig.2.

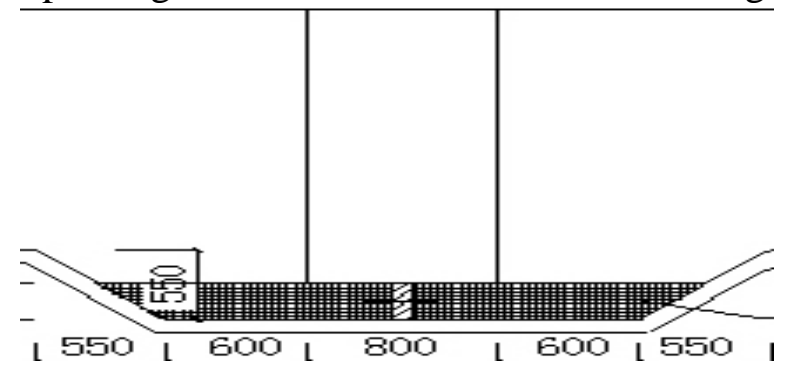

Figure 1 The profile of the post pouring belt on the baseboard

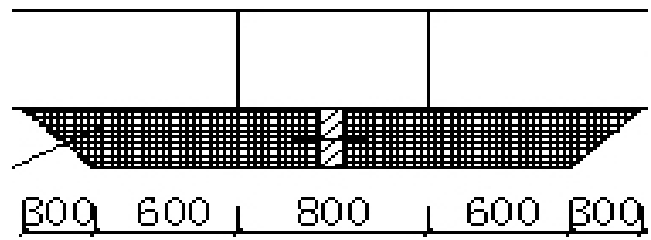

Figure. 2 The profile of the post pouring belt on the wall and the roof

The basement floor of the project with a thickness of $30 \mathrm{~cm}$ and C30, the impermeability of concrete P6. The concrete wall is $30 \mathrm{~cm} \mathrm{C30} \mathrm{P6,} \mathrm{the} \mathrm{impermeability} \mathrm{of} \mathrm{concrete.} \mathrm{The} \mathrm{basement} \mathrm{roof} \mathrm{with} 35 \mathrm{~cm}$ thick C35, P6 the impermeability of concrete.

The construction technology of the post pouring belt.The construction technology of the post pouring belt on the baseboard. The bottom formwork construction method of the post pouring belt. Plate thickness is $0.3 \mathrm{~m}$, the post pouring belt by 2 with 20 steel frame, at the bottom of post cast strip is arranged at the hy rib side formwork support, binding on the steel skeleton. In order to ensure the construction quality, the post pouring belt shall be welded on the steel skeleton reinforced on the floor. The measure and fixed hy rib plate, which can ensure the position accuracy and can resist template pouring belt lateral pressure, the principle is to set the diagonal bar which acting on the side templates and generate tension on the lateral pressure and to offset some of the post pouring belt arranged to support part of lateral pressure cancellation of concrete.

The temporary protection construction method for pouring bottom. During the period of post pouring belt vacant, to prevent debris, sewage into the closed, may take the following measures: on both sides of masonry $240 \mathrm{~mm}$ wide, $300 \mathrm{~mm}$ high brick belt at the bottom pouring cement mortar, masonry M10 MU5 brick, brick and floor surface corner with 1: 2 with $18 \mathrm{~mm}$ cement mortar plastering, closed upper thick plywood.

The waterproof construction method for pouring bottom. Concrete construction, the construction of a layer of polyurethane waterproof coating layer on the cushion. In order to enhance the impermeability and waterproof, prevent the influx of groundwater under the floor.

The construction technology of the post pouring belt on the wall. Because of narrow construction site surrounding the project, the construction shall be carried out in the backfill, leveling the ground and hardened. The bottom plate and beam plate template, the template for the first time did not open, then do not have to re set. But for the wall, because before the template has been removed, then re erection of formwork and formwork supports, re erection of formwork should be close to the concrete surface has been pouring, to avoid leakage, therefore to take interim measures of protection on the wall of the post pouring belt. The concrete construction is in the wall post cast strip by brick retaining wall was closed, with a beam on top, forming a protection for concrete wall pouring facilities, and safety protection measures and drainage measures on the edge.

In order to prevent debris into the concrete post pouring belt, using plywood closed. 
The waterproof construction method of the concrete post pouring belt wall are the following: the design of concave and convex grooves; the middle part is provided with a water stop plate or rubber waterstop; the central post BW grouting. Considering the engineering construction site around the small, waterstop construction more difficult, it is difficult to ensure the quality of construction, the construction of the pouring belt of central reserve side groove with BW grouting method.

The construction technology of the post pouring belt on the roof. The project is used in roof beamless roof structure, the basement roof is $35 \mathrm{~cm}$ thick C35, P6 the impermeability of concrete. For the roof floor without beam part of the pouring belt construction technology method and the same floor of the late poured band. The closure of the post pouring belt, the roof template pouring position shall not be removed. In order to ensure the safety of structure system, roof of the pouring belt uses template support system and platform independent, templates, disconnect the connection, does not affect the removal of template platform.

The quality assurance measure on the construction technology of the post pouring belt. In the construction process, should be supported by steel tubes after pouring belt on both sides, to ensure that the component and structure of the bearing capacity and the stability of construction stage.

After pouring concrete pouring belt before, must be in accordance with the requirements of the whole section construction joint treatment, removal of debris, loose gravel, cement film surface and the weak layer of concrete, rust of reinforced concrete, and the two sides cut hair, rinse with water, sufficient to maintain two side concrete moist, generally not less than 24 hours. If both sides is not chiseled concrete pouring concrete after pouring in, it will be difficult to ensure that the bond strength of new old concrete, treatment is not good in the post pouring belt on both sides of two edges caused by air crack, easy to water seepage.

Before pouring the concrete of the pouring belt near the local protection, should be covered, temporary railings around the enclosure measures, ensure the steel being trampled and construction site safety.

After pouring concrete strength to meet the design requirements after the removal of the post pouring belt template.After pouring concrete pouring, in addition to covering the surface wet sack water conservation, but also in the post pouring belt on both sides of 2 bricks masonry wall to water conservation, often artificial watering, the curing time is 2 weeks.

After pouring concrete pouring block must be retained according to the specifications. Impermeability requirements, shall be made in accordance with the relevant provisions of impermeability test block. And post pouring belt should be used to improve the concrete casting level, early strength, shrinkage compensation than the corresponding component strength grade of concrete, mix design should be through the calculation of the ratio test.

The preventing measure of the crack.Temperature control. The variety and dosage of cement concrete determines the internal temperature. Concrete is composed of cement with lower hydration heat production. In the premise of ensuring the strength of concrete, the appropriate use of retarder superplasticizer admixture, etc. In order to reduce the amount of cement per cubic meter of concrete, reduce water consumption, reduce the hydration heat, to avoid the temperature of concrete internal and external caused by excessive crack. Temperature measurement in the construction process is to grasp the actual condition of the internal temperature of concrete. In order to prevent exceeding the critical temperature cracks of mass concrete temperature difference inside and outside.

The control of concrete mixture ratio. In the design of concrete mix ratio, the water cement ratio influences the concrete shrinkage. The greater the water cement ratio, the greater is the contraction. In order to control the water cement ratio, reduce the dosage of cement, it should choose the lesser shrinkage of cement and fly ash cement.

The control of the construction technology. Remove the concrete surface to prevent the bleeding of concrete mortar surface because of too much and shrinkage crack. At the same time, in the after 
pouring, it should add a layer of clean gravel in the concrete surface, increase the amount of pressure. Avoid constructing in the hot weather or a larger temperature difference between day and night time. Conservation measures are reasonable. The purpose of curing is to allow normal hardening of concrete, reduce the influence by the environment. The key is to try to reduce concrete internal temperature, to close to the ambient temperature, reduce the internal and external station temperature, prevent crack. To prevent the generation of cracks in the construction of concrete pouring, the early curing of concrete is very important. The use of wood curing 20 days, keep the template completely wet, to the hydration process of concrete mixing water in a humid environment. Water conserving the internal and external side of the basement by the continuous cycle mode.

\section{Summary}

The post pouring belt in the basement in the construction of more and more extensive application. Not only can solve the problem of the settlement of building foundation structure effectively by setting the post pouring belt, but also ensure the quality of building structure. [10] In the actual construction, the basement construction of the pouring belt is a systematic and complex project, the influence factors are relatively more.

In order to ensure the construction quality, the builder must accurately grasp and understanding of the pouring belt of construction techniques, to avoid all kinds of quality problems appeared in the process of the construction of the late poured band. In addition, because of the post pouring belt cleaning more difficult, should strengthen the protection of the normal, so that it can effectively ensure the post pouring belt use effect.

\section{References}

[1] C.Y.Xu:Shangxi Architecture, Vol. 39 (2013) No.8, p.115.

[2] J.X.Ren:Construction technology of underground engineering(Northwestern Polytechnical University Press, China,2012).

[3] J.Gong and Y.L.Wang:Construction Technology, Vol.41(2012) No.3, p.8.

[4] L.Y.Chen,J.Zhang and B.C.Wang:Architecture Technology, Vol.43(2012) No.11, p.974.

[5] B.H.Han:Shangxi Architecture, Vol. 37 (2011) No.12, p.102.

[6] Y.J.Liu:Shangxi Architecture, Vol. 38 (2012) No.3, p.93.

[7] Z.F. Li: Technology and Market, Vol.19(2012) No.7, p.158.

[8] J.R.Qiu:Architecture Technology, Vol.42(2012) No.2, p.131.

[9] Z.X.Guo: Civil engineering construction(Southeast University Press, China,2012).

[10] J.B.Chen,Y.H.Li,H.Z.Ma:Sichuan Building Science, Vol.40(2014) No.5, p.333. 